\title{
Optimization Study of Heat Pumps Using Refrigerant Blends - Ejector Versus Expansion Valve Systems
}

\author{
Eivind Brodal* and Oddmar Eiksund \\ Engineering Science and Safety IVT, UiT-The Arctic University of Norway, Norway
}

\section{Abstract}

This article investigates tap water heating systems to highlight an ongoing debate. Some report that $\mathrm{CO}_{2}$-based transcritical heat pumps with an ejector have the best coefficient of performance (COP), while others report that blend-based refrigerant systems (without an ejector) are better. In the literature, however, these systems are only compared with conventional heat pump designs, and not against each other, making it difficult to conclude which design is the best. In addition, the outcome of combining the two modifications has not been explored extensively. This article investigates the performance of heat pumps using mixtures of $\mathrm{CO}_{2}$ and propane, with and without an ejector or a suction gas heat exchanger. It presents a novel method for modeling blend-based heat pumps with an ejector using an optimization approach and a minimum allowed temperature pinch in heat exchangers. A sensitivity study explores how the heat pump performance depends on operating conditions, ejector efficiency and the refrigerant blend. The sensitivity studies allow for the comparison of the heat pump designs. For example, the results show that it is inefficient to use $\mathrm{CO}_{2}$ and propane blends in systems with an ejector. A blend-based system with a suction gas heat exchanger was found to outperform a $\mathrm{CO}_{2}$-based system with an ejector if either the tap water is above $25^{\circ} \mathrm{C}$, the ejector efficiency is below 0.17 , or the temperature of the heat source is reduced with more than $10 \mathrm{~K}$ when flowing through the evaporator.

\section{Keywords}

Heat pump; Ejector; Zeotropic; Optimization; Temperature pinch; Internal heat exchanger

* Corresponding author. Tel.: +47 77660364. E-mail: eivind.brodal@uit.no

\begin{tabular}{|c|c|c|c|}
\hline \multicolumn{2}{|c|}{ Nomenclature } & \multicolumn{2}{|c|}{ Subscripts } \\
\hline COP & Coefficient of performance [-] & comp & Compressor \\
\hline$f_{1}$ & Mass fraction $\mathrm{CO}_{2}$ at point 1 in Figure $1[-]$ & ex & Heat exchanger \\
\hline GWP & Global warming potential & is & Isentropic \\
\hline$h$ & Specific enthalpy $\left[\mathrm{kJ} \mathrm{kg}^{-1}\right]$ & $\min$ & Minimum \\
\hline $\mathrm{IHX}$ & Internal heat exchanger & pinch & Pinch point \\
\hline$k$ & Penalty factor $[-]$ & rec & Recovered \\
\hline$m$ & Mass [kg] & & \\
\hline$\dot{m}$ & Mass flow $\left[\mathrm{g} \mathrm{s}^{-1}\right]$ & & \\
\hline ODP & Ozone depletion potential & & \\
\hline$P$ & Power $[\mathrm{kW}]$ & & \\
\hline$p$ & Pressure [bar] & & \\
\hline$p_{\mathrm{r}}$ & Pressure ratio of the compressor $[-]$ & & \\
\hline$\Delta p_{\mathrm{ex}}$ & Pressure drop in heat exchangers [bar] & & \\
\hline$q$ & Penalty function [-] & & \\
\hline
\end{tabular}




\begin{tabular}{|l|l|}
\hline$Q$ & Vapor quality [-] \\
\hline$S$ & Specific entropy [kJ kg-1 $\left.\mathrm{K}^{-1}\right]$ \\
\hline $\mathrm{SGHX}$ & Suction gas heat exchanger \\
\hline$T$ & Temperature [ $\left.{ }^{\circ} \mathrm{C}\right]$ \\
\hline$\Delta T_{\text {min }}$ & $\begin{array}{l}\text { Minimum allowed temperature approach in the heat } \\
\text { exchangers [K] }\end{array}$ \\
\hline$\Delta T_{\text {pinch }}$ & $\begin{array}{l}\text { Minimum temperature difference between two fluids } \\
\text { exchanging heat in an exchanger (calculated by the } \\
\text { process model) [K] }\end{array}$ \\
\hline$\eta_{\text {comp }}$ & Isentropic efficiency compressor [-] \\
\hline$\eta_{\text {ejector }}$ & Ejector efficiency [-] \\
\hline$\eta_{\text {modelled ejector }}$ & Ejector efficiency (calculated by the process model) [-] \\
\hline$\mu$ & Entrainment ratio ejector [-] \\
\hline
\end{tabular}

\section{Introduction}

For over two decades carbon dioxide $\left(\mathrm{CO}_{2}\right)$ based heat pumps for water heating have been known to outperform non-environmentally friendly alternatives if the feed water is cold, because a transcritical $\mathrm{CO}_{2}$ process matches the temperature profile of the water in the gas cooler (Nekså et al., 1998). Two modifications regarding heat pump systems for water heating have been discussed recently. One method is to reduce thermodynamic losses connected to temperature differences in heat exchangers by introducing zeotropic refrigerant blends (Zhang et al., 2017a), and the other is to reduce thermodynamical losses by replacing the conventional expansion valve with a two-phase ejector (Tashtoush et al., 2019). The objective of this article is to evaluate which of these two methods is best, and to investigate if systems with both modifications are even better. In order to do this, pure and binary-blends with carbon dioxide (R744) and propane (R290) are investigated. Both $\mathrm{CO}_{2}$ and propane are natural refrigerants which have recently gained more attention, since synthetic refrigerants with a large global warming potential (GWP) or a non-zero ozone depletion potential (ODP) are being phased out to mitigate global warming and ozone depletion.

The improvement in energy efficiency realizable through the inclusion of an ejector is well documented for pure refrigerants, e.g. by Banasiak et al. (2012). Heat pumps for water heating are now often constructed as transcritical pure $\mathrm{CO}_{2}$-based processes, which have a back pressure valve with adjustable set pressure. To maximize the coefficient of performance (COP), the discharge pressure is typically held high by the back pressure valve, which makes the ejector expansion gain often significant in such processes. Ejectors have also become popular since they have no moving parts and are easy to build (inexpensive).

A large number of studies have investigated mixed-refrigerant systems without an ejector. Zhang et al. (2017a), for example, studied six binary mixtures with $\mathrm{CO}_{2}$, and identified systems using blends of $\mathrm{CO}_{2}$ and propane to have the best COP. Blends of $\mathrm{CO}_{2}$ and butane have also been suggested (Sarkar and Bhattacharyya, 2009). A large theoretical study on zeotropic binary $\mathrm{CO}_{2}$ blends with low-GWP refrigerants was published by Dai et al. (2015), which is perhaps the most comprehensive study relevant for water heating. However, this study did not include heat pumps with an internal heat exchanger (IHX), which can improve the performance (Sarkar and Bhattacharyya, 2009; Cao et al., 2019). Systems using zeotropic blends can obtain a large COP if there is a close match between the temperature profile of the refrigerant and the heating and cooling demand in the different exchangers. In order to describe the benefit of using refrigerant blends, theoretically, it is therefore important to consider the temperature profile of the heat sink and heat source. Comparative studies of blend-based systems without ejectors, e.g. by Dai et al. (2015) and Sarkar and Bhattacharyya (2009), have modelled heat pumps using constraints related to a minimum allowed temperature approach inside each heat exchanger. This method is believed to be more accurate than defining refrigerant temperatures directly, e.g. at the evaporator and gas cooler outlets (Zhao et al., 2015). 
Much of the previous zeotropic heat pump studies, such as Sarkar and Bhattacharyya (2009) and Dai et al. (2015), is based on iterative search for the best design-dependent heat pump parameters fulfilling the constraints. However, the number of design dependent variables increase by adding an ejector or an IHX. The minimum allowed temperature constraints are therefore implemented through advanced multivariable optimization algorithms, inspired by studies of large natural gas liquefaction units (Ding et al., 2017).

Blend-based units with an ejector have been investigated experimentally by Bai et al. (2018) and Bai et al. (2019), but is a relatively new and unexplored topic as discussed in the literature review studies by Zhang et al. (2017a) and Tashtoush et al. (2019). A large portion of these papers, such as the study by Yan et al. (2016), suggest that systems with blended refrigerants can obtain better COP than systems with a single refrigerant. Historically, simplified models have often been applied to azeotropic behaving mixtures by neglecting changes in the refrigerant concentration, for example by Hernandez et al. (2014) who modelled R410A-based systems with a temperature glide less than 0.15 K. Others have modelled zeotropic refrigerant-based processes with a similar approach, such as Lontsi et al. (2016) study of systems using R404A and R407C. However, zeotropic refrigerant-based heat pumps with an ejector have different refrigerant blends flowing through the evaporator and the gas cooler due to the separation of gas and liquids in the process. Only five articles were identified modelling the different compositions (Liu et al., 2015; Zhao et al., 2015; Li et al., 2016; Yan et al., 2016; Liu et al., 2018), and neither of these modelled the temperature profile of the heat source or the heat sink. These articles also assumed that the refrigerant blend was at its dew point at the evaporator outlet, but this is not necessarily optimal.

The main scope of this article is to develop a method for modeling ejector-based heat pump systems using refrigerant blends, and to improve our knowledge of how to construct systems with large COP. That is, should systems be designed with refrigerant blends, an ejector, or an IHX. The approach is based on multivariable optimization where each heat exchanger is modelled through a minimum temperature pinch constraint. To the author's best knowledge, this is also the first article to implement the ejector efficiency through a constraint in the optimization work.

\section{Method}

The method section describes the different heat pump designs and scenarios investigated, and explains the process model and optimization approach.

\subsection{Heat Pump Design}

Three different heat pump systems (A, B and C) are investigated in this study, as described in Figure 1. Heat pump $A$ is the base case investigated by Dai et al. (2015). Heat pump $B$ is modified with an $\mathrm{IHX}$ operating as a suction gas heat exchanger (SGHX). Heat pump $\mathrm{C}$ is modified to include an ejector. It is assumed that the vapor quality leaving the evaporator $\left(Q_{8}\right)$ is optimized in $C$ with respect to COP, but also designs where the gas is at dew point are modeled $\left(C^{*}\right)$. Figure 2 shows optimized heat pump A and B processes for a selection of different refrigerant blends. Only designs with zero superheating at the evaporator outlet are considered, as is typically assumed in previous studies involving zeotropic refrigerants (Dai et al., 2015 and Sarkar and Bhattacharyya, 2009). 

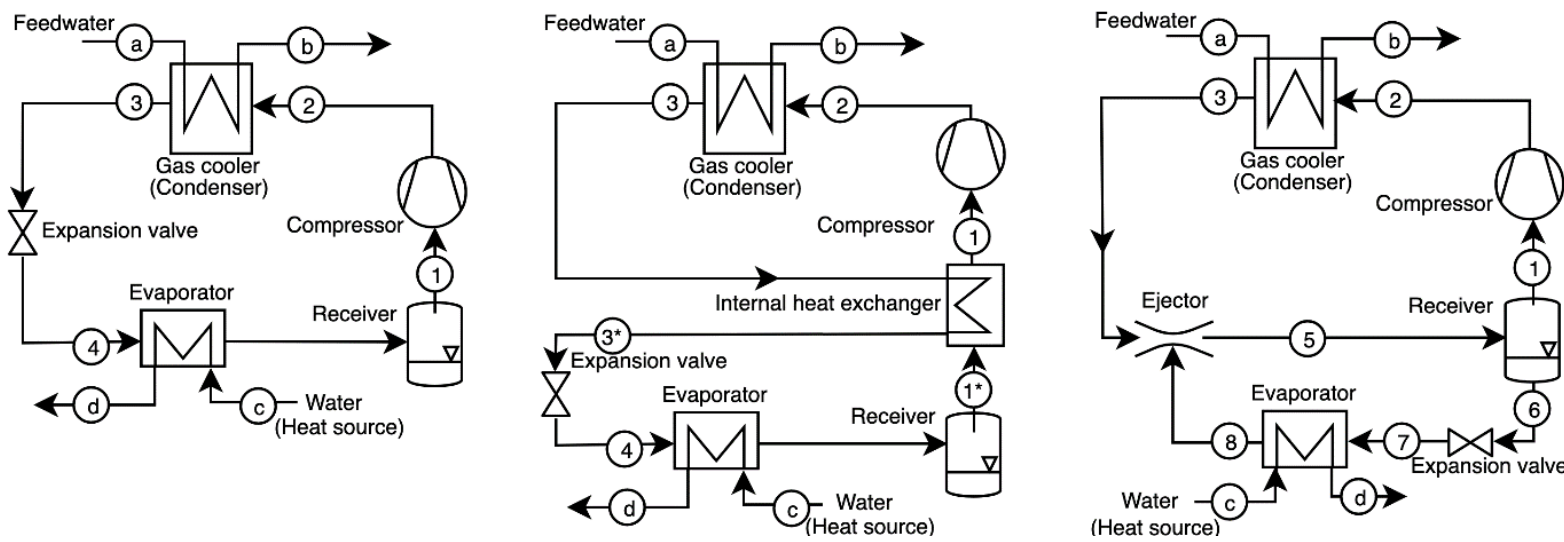

Figure 1. Flow diagrams of heat pump $A$, heat pump $B$ with an IHX/SGHX, and heat pump $C / C^{*}$ with ejector expansion.
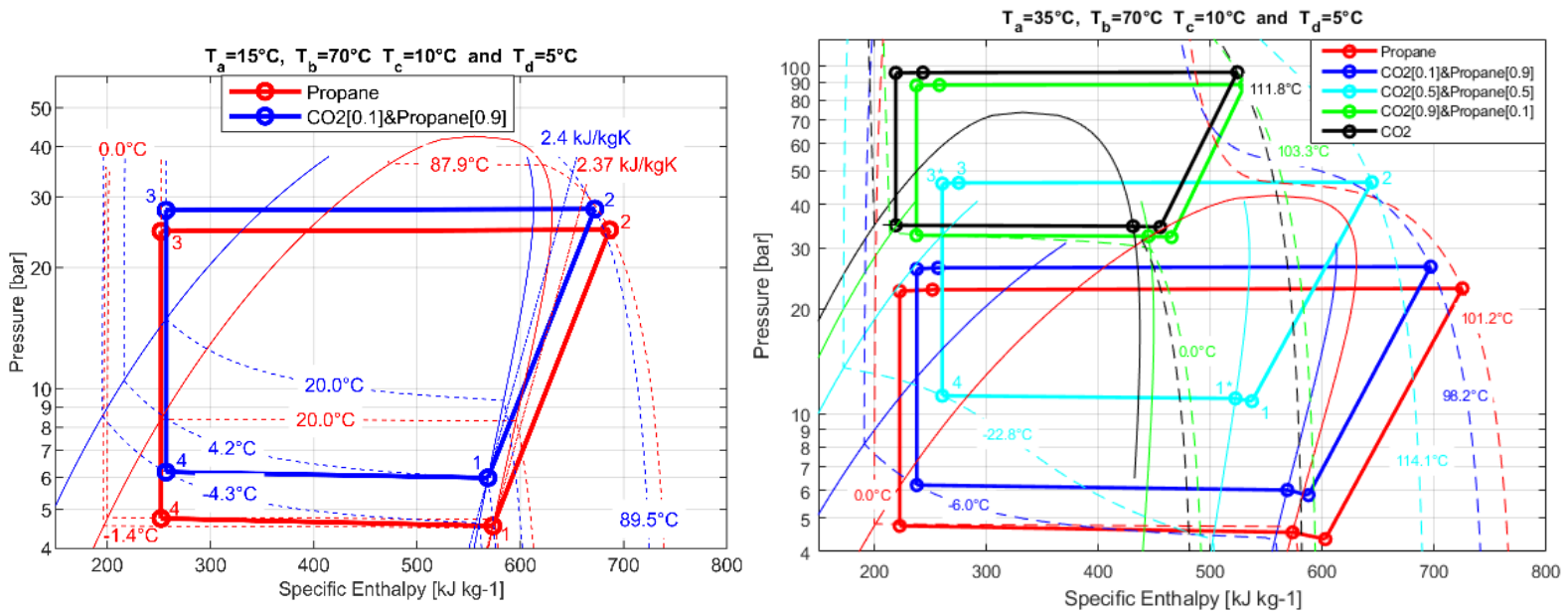

Figure 2. Optimized heat pump A processes for two different refrigerants (left), and optimized heat pump B processes for five different refrigerants (right).

\subsection{Heat Pump Process Modelling}

In this work the coefficient of performance, i.e. the ratio between the heating duty $\left(P_{\text {gas cooler }}\right)$ and the compressor power $\left(P_{\text {comp }}\right)$, is used to describe the system performance:

$$
\text { COP }=\frac{P_{\text {gas cooler }}}{P_{\text {comp }}}=\frac{h_{2}-h_{3}}{h_{2}-h_{1}}
$$

using the numbering convention in Figure 1.

\subsubsection{Process Parameters}

Process performance depends on a variety of parameters including the refrigerant blend entering the compressor at point $1\left(f_{1}\right)$, the pressure drop in the heat exchangers $\left(\Delta p_{\mathrm{ex}}\right)$, the minimum allowed temperature approach in the heat exchangers $\left(\Delta T_{\text {min }}\right)$, the compressor efficiency $\left(\eta_{\text {comp }}\right)$ and pressure ratio $\left(p_{\mathrm{r}}=p_{2} / p_{1}\right)$, the ejector efficiency $\left(\eta_{\text {ejector }}\right)$ and the mass fraction of gas entering the ejector from the evaporator $\left(Q_{8}\right)$. The input parameters for each of the different heat pump models are shown in Table 1.

Table 1. Modelling input parameters for different heat pump designs. Values applied in this study are listed in Table 4 and 5.

\begin{tabular}{cl}
\hline Heat pump & Input parameters \\
\hline A & $P_{\text {gas cooler }}, f_{1}, T_{\mathrm{a}}, T_{\mathrm{b}}, T_{\mathrm{c}}, T_{\mathrm{d}}, T_{1}, T_{3}, p_{2}, \Delta p_{\mathrm{ex}}, \eta_{\text {comp }}$ and $\Delta T_{\min }$ \\
\hline B & $P_{\text {gas cooler }}, f_{1}, T_{\mathrm{a}}, T_{\mathrm{b}}, T_{\mathrm{c}}, T_{\mathrm{d}}, T_{1}, T_{3}, T_{1^{*}}, p_{2}, \Delta p_{\mathrm{ex}}, \eta_{\mathrm{comp}}$ and $\Delta T_{\min }$ \\
\hline C & $P_{\text {gas cooler }}, f_{1}, T_{\mathrm{a}}, T_{\mathrm{b}}, T_{\mathrm{c}}, T_{\mathrm{d}}, T_{8}, T_{3}, p_{2}, p_{\mathrm{r}}, \Delta p_{\mathrm{ex}}, \eta_{\text {comp }}, \Delta T_{\min }, \eta_{\text {ejector }}$ and $Q_{8}$ \\
\hline C $^{*}$ & $P_{\text {gas cooler }}, f_{1}, T_{\mathrm{a}}, T_{\mathrm{b}}, T_{\mathrm{c}}, T_{\mathrm{d}}, T_{8}, T_{3}, p_{2}, p_{\mathrm{r}}, \Delta p_{\mathrm{ex}}, \eta_{\text {comp }}, \Delta T_{\min }, \eta_{\text {ejector }}$ and $Q_{8}=1$ \\
\hline
\end{tabular}


For a given set of input parameters, the system model calculates enthalpies and other values such as the temperature pinch in the evaporator $\left(\Delta T_{\text {pinch evaporator }}\right)$, gas cooler $\left(\Delta T_{\text {pinch gas cooler }}\right)$ and IHX ( $\left.\Delta T_{\text {pinch IHX }}\right)$, as well as the ejector efficiency $\left(\eta_{\text {modelled ejector }}\right)$. The minimum allowed approach temperature $\Delta T_{\min }$ in the heat exchangers and the ejector efficiency $\eta_{\text {ejector }}$ are not direct input variables in the process model, but are implemented through the optimization constraints listed in Table 2 (see section 2.4).

Table 2. Process constraints in the optimization work. In this work, $\Delta T_{\min }$ is assumed to be $5.0 \mathrm{~K}$ (see Table 5).

\begin{tabular}{lll}
\hline Case A & Case B & Case C and C* \\
\hline$\Delta T_{\text {pinch evaporator }} \geq \Delta T_{\min }$ & $\Delta T_{\text {pinch evaporator }} \geq \Delta T_{\min }$ & $\Delta T_{\text {pinch evaporator }} \geq \Delta T_{\min }$ \\
\hline$\Delta T_{\text {pinch gas cooler }} \geq \Delta T_{\min }$ & $\Delta T_{\text {pinch gas cooler }} \geq \Delta T_{\min }$ & $\Delta T_{\text {pinch gas cooler }} \geq \Delta T_{\min }$ \\
\hline & $\Delta T_{\text {pinch IHX }} \geq \Delta T_{\min }$ & $\eta_{\text {modelled ejector }}=\eta_{\text {ejector }}$ \\
\hline
\end{tabular}

\subsubsection{Thermodynamic Property Calculations}

Thermodynamic properties, such as specific enthalpy $(h)$, specific entropy $(s)$, vapor quality $(Q)$ are mainly calculated using CoolProp (Bell et al., 2014). CoolProp applies the equations of state (EOS) described by Span and Wagner (1996) and Lemmon et al. (2009) for pure $\mathrm{CO}_{2}$ and pure propane, respectively. For blends of $\mathrm{CO}_{2}$ and propane, CoolProp uses the GERG-2008 (Kunz and Wagner, 2012) equation of state.

To evaluate properties for mixtures, such as $h$, CoolProp is limited to only three input pairs ( $p T, p Q$ and $T Q$ ) and because of this, TREND (Span et al., 2016), which is another "state of the art" property model, is sometimes used. TREND is based on the same EOS as CoolProp for blends of $\mathrm{CO}_{2}$ and propane, but uses different numerical algorithms which can solve input options like $p s$. This is necessary in order to calculate enthalpy differences in isentropic processes related to the compressor and ejector performance. For different $p T$ input, for example, TREND and CoolProp typically calculate $h$ or $s$ values where the first five digits are identical for $\mathrm{CO}_{2}$ and propane blends. The difference was always less than $0.01 \%$ for inputs relevant for the heat pumps in this study, demonstrating high consistency.

\subsection{Component Modelling}

Figure 1 illustrates the equipment components that make up the different heat pumps. Expansion valves are modelled assuming that the enthalpy is unchanged (i.e. as an isenthalpic expansion), the other components are modelled as described below.

\subsubsection{Heat Exchanger Performance Modelling}

All heat exchangers are assumed to operate counter current. Several approaches can be considered for modelling heat exchangers. This study is based on an optimization technique with minimum allowed temperature approach. However, the temperature pinches in each of the different heat exchangers are input parameters in the optimization process, and not direct input parameters in the process model. The temperature pinches are calculated by the process model, and forced to equal the minimum allowed temperature pinch in the exchangers $\left(\Delta T_{\min }\right)$ by implementing constraints in the optimization (see Table 2). Examples of the heat exchanger temperature profiles for the different heat pump processes in Figure 2 and 3 are illustrated in the supplementary files. 
Pressure drop in heat exchangers is often ignored in zeotropic refrigerant studies, e.g. by Dai et al. (2015). However, pressure drop can be an important loss factor in exchangers operating at lower pressures, and in ejector systems where the vapor fraction out of the evaporator $\left(Q_{8}\right)$ is low due to the large mass flow through the evaporator. In this work, all heat exchangers are modelled with fixed pressure drops $\left(\Delta p_{\mathrm{ex}}\right)$. The pressure drop profile in each exchanger is also important for the internal pinch point, and a linear pressure loss with respect to the amount of heat transferred is assumed for each exchanger (Brodal and Jackson, 2019). For the gas cooler, e.g., the pressure profile becomes:

$$
p=p_{2}-\Delta p_{\mathrm{ex}}\left(\frac{h-h_{2}}{h_{3}-h_{2}}\right) \text { for } h_{2} \geq h \geq h_{3} \text {. }
$$

\subsubsection{Compressor Performance Modelling}

Compressor performance is modelled using isentropic efficiency:

$$
\eta_{\text {comp }}=\frac{P_{\text {comp is }}}{P_{\text {comp }}}=\frac{h_{2, i s}-h_{1}}{h_{2}-h_{1}},
$$

where $P_{\text {comp,is }}$ is an isentropic compression process from point 1 to pressure $p_{2}$.

\subsubsection{Receiver Modeling}

For all heat pump designs, the composition of the refrigerant in the gas exiting the receiver is implemented directly from the mass fraction of $\mathrm{CO}_{2}$ input $\left(f_{1}\right)$. For systems with an ejector, the dew point gas $\left(Q_{1}=1\right)$ and bubble point liquid $\left(Q_{6}=0\right)$ are separated by the receiver, as illustrated by Figure 3. For systems with pure refrigerants, $h_{6}$ can be calculated directly since the pressure $p_{6}=$ $p_{1}=p_{2} / p_{r}$ is given by the input parameters and that $T_{6}=T_{1}$. Systems with zeotropic refrigerant blends are more difficult to model due to different concentrations in outlet and inlet streams. In such systems, the mass fraction of $\mathrm{CO}_{2}$ in the liquid leaving the receiver $\left(f_{6}\right)$ must be evaluated before calculating $h_{6}$. This is done by an iterative search for the blend that has bubble point at $T_{1}$ and $p_{1}$.

The mass fraction of $\mathrm{CO}_{2}$ in the receiver inlet is $f_{5}=\left(\dot{m}_{6} f_{6}+\dot{m}_{1} f_{1}\right) /\left(\dot{m}_{6}+\dot{m}_{1}\right)$. System energy conservation in steady state $\left(P_{\text {evaporator }}=P_{\text {gas cooler }}-P_{\text {comp }}\right)$ gives the relation between the outlet receiver mass flows:

$$
\mu=\frac{\dot{m}_{6}}{\dot{m}_{1}}=\left(\frac{P_{\text {gas cooler }}-P_{\text {comp }}}{P_{\text {evaporator }}}\right) \cdot \frac{\dot{m}_{6}}{\dot{m}_{1}}=\frac{h_{1}-h_{3}}{h_{8}-h_{6}}
$$

which is known as the entrainment ratio. Unlike the work by Yan et al. (2016) and Zhao et al. (2015), all the formulas are derived with enthalpy-differences related to fluids with the same concentrations, as done by Liu et al. (2015) and Liu et al. (2018). This is important since enthalpy and entropy are relative properties, and different blends operate with different reference states. 

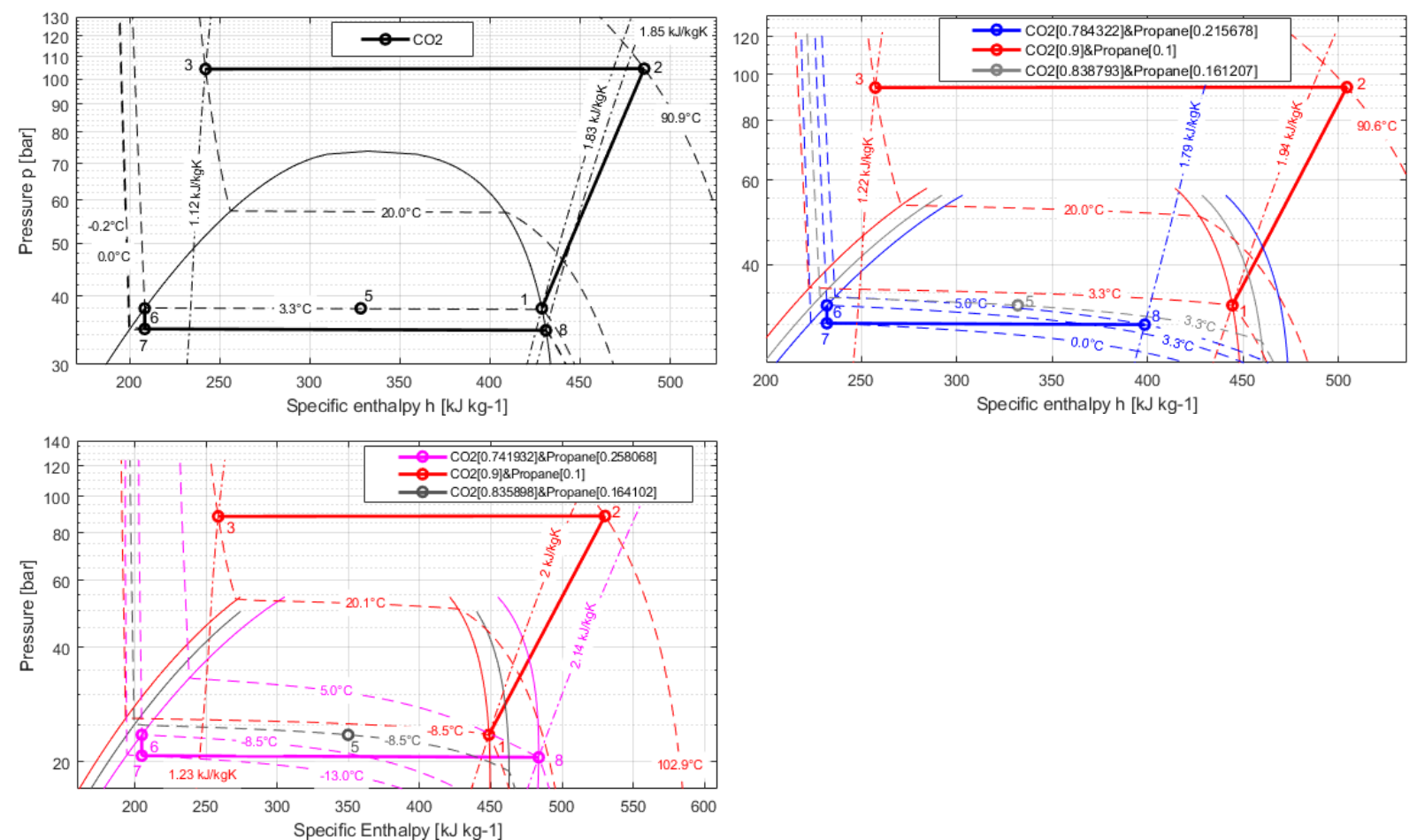

Figure 3. Optimized processes with a 0.34 ejector efficiency and $T_{a}=15{ }^{\circ} \mathrm{C}, T_{b}=70{ }^{\circ} \mathrm{C}, T_{c}=10{ }^{\circ} \mathrm{C}$ and $T_{d}=5{ }^{\circ} \mathrm{C}$. Top left: $\mathrm{C}$ \& $C^{*}$ processes with pure $\mathrm{CO}_{2}$. Top right: $\mathrm{C}^{*}$ with zeotropic blend. Bottom: $\mathrm{C}$ with zeotropic blend. Temperature approach in the different heat exchangers are illustrated in the supplementary files.

\subsubsection{Ejector Performance Modelling}

The ejector efficiency introduced by Elbel and Hrnjak (2008) is used, which compares the amount of expansion work recovered by the ejector with the maximum possible expansion work recovery potential:

$$
\eta_{\text {ejector }}=\frac{\dot{m}_{6}\left(h_{8, \mathrm{is} \rightarrow p_{5}}-h_{8}\right)}{\dot{m}_{1}\left(h_{3}-h_{3, \mathrm{is} \rightarrow p_{5}}\right)},
$$

where $h_{8, \text { is } \rightarrow p_{5}}$ and $h_{3, \text { is } \rightarrow p_{5}}$ are the enthalpies obtained by isentropic processes from point 8 and 3 , respectively, to the ejector outlet pressure $\left(p_{5}\right)$. Eqs. (4) and (5) can also be combined as:

$$
\eta_{\text {ejector }}=\frac{\left(h_{1}-h_{3}\right)\left(h_{\left.8, \text { is } \rightarrow p_{5}-h_{8}\right)}\right.}{\left(h_{8}-h_{6}\right)\left(h_{3}-h_{3, \text { is } \rightarrow p_{5}}\right)} \text {. }
$$

The systems described here have $\eta_{\text {ejector }}$ as an input parameter. In addition to the vapor quality $Q_{8}$, some other information, such as $T_{8}$ or $p_{8}$, is necessary in order to evaluate the enthalpies $h_{8, \text { is } \rightarrow p_{5}}$ and $h_{8}$. Hence, Eq. (6) is a standard root problem with respect to $T_{8}$, which can be solved numerically (Zhao et al., 2015; Brodal and Jackson, 2019). However, a different and new approach was tested which is believed to be better. In the new approach $T_{8}$ is optimized together with the other process parameters using a multivariable optimization algorithm, and Eq. (6) is implemented indirectly through the constraint $\eta_{\text {modelled ejector }}=\eta_{\text {ejector }}$, where $\eta_{\text {modelled ejector }}$ is the value of the right hand side of Eq. (6). The vapor fraction in the ejector outlet is given as:

$$
Q_{5}=\frac{\dot{m}_{1}}{\dot{m}_{5}}=\frac{\dot{m}_{1}}{\dot{m}_{1}+\dot{m}_{6}}=\frac{1}{1+\mu} \text {. }
$$

\subsection{Heat Pump Optimization}

The large number of input parameters and constraints (see Table 1 and 2), makes it difficult to analyze and compare systems directly. In this work, the problem size is reduced through optimization. For example, instead of analyzing how the pressure input $p_{2}$ affects the COP, it is assumed that $p_{2}$ is optimal with respect to COP, which is the case if the back pressure valve set point 
is controlled by an intelligent system. Similarly, if the ejector and heat exchangers are designed for a particular set of operating conditions, it can also be assumed that their geometries and sizes to some extent can be optimized for the task. The objective function in the minimization problem is:

$$
\min \{-\mathrm{COP}\},
$$

where the variables being optimized are listed in Table 3. A flow chart of the main process calculations is shown in Figure 4. Note that, including $f_{1}$ as an optimization parameter can be difficult due to local optimums (see Figure 5).

\begin{tabular}{cccc}
\multicolumn{4}{c}{ Table 3. Process parameters being optimized. } \\
\hline Case A & Case B & Case C* & Case C \\
\hline$T_{1}$ & $T_{1}$ & $T_{8}$ & $T_{8}$ \\
\hline$T_{3}$ & $T_{3}$ & $T_{3}$ & $T_{3}$ \\
\hline$p_{2}$ & $p_{2}$ & $p_{2}$ & $p_{2}$ \\
\hline \multicolumn{5}{c}{$T_{1^{*}}$} & $p_{\mathrm{r}}$ & $p_{\mathrm{r}}$ \\
\hline \multicolumn{4}{c}{} \\
\hline
\end{tabular}

A new method for implementing the ejector efficiency is applied. In previous articles, processes have always been calculated with the correct ejector efficiency during the whole optimization (Zhao et al., 2015; Brodal and Jackson, 2019). However, it is easier to calculate the ejector efficiency $\eta_{\text {modelled ejector }}$ with a given temperature $T_{8}$, than to find the correct temperature $T_{8}$ given the ejector efficiency $\eta_{\text {ejector }}$ since this involves an iterative search to find $f_{6}$ inside another algorithm solving the root problem described in Eq. (6). Since a multivariable optimization algorithm is already used to find the best COP, the correct temperature $T_{8}$ can be found in the optimization work by adding $T_{8}$ as an optimization parameter while applying either a nonlinear constraint or a penalty, ensuring that $\eta_{\text {modelled ejector }}=\eta_{\text {ejector }}$ in the final result. Hence, much of the programing complexity has been removed from the process model calculating COP, while the optimization problem is only increased slightly with one additional optimization variable and one additional constraint. A numerical study comparing these methods in greater detail could be conducted in the future.

In most cases a large sequence of runs using the Fmincon, Fminsearch and Particleswarm algorithms from the MATLAB Optimization Toolbox was applied to obtain an accurate optimization result.

Fminsearch uses a simplex algorithm developed by Nelder and Mead (1965), Particleswarm applies a stochastic-based algorithm (Kennedy and Eberhart, 1995), and Fmincon uses sequential quadratic programming (sqp) gradient-based method (Spellucci, 1998). When using Fmincon, COP is optimized through a direct implementation of the constraints listed in Table 2. Fminsearch and Particleswarm cannot optimize problems with non-linear constraints directly, but the constraints can be implemented indirectly through penalties. For heat pump A, the minimization problem is solved as:

$$
q_{\mathrm{B}}=q_{\mathrm{A}}=-\operatorname{COP}+k_{1} \cdot\left[\max \left(0, \Delta T_{\min }-\Delta T_{\text {pinch evaporator }}\right)\right]^{2}+k_{2} \cdot\left[\max \left(0, \Delta T_{\min }-\Delta T_{\text {pinch evaporator }}\right)\right]^{2},
$$

where $k_{i}$ are penalty factors, $\Delta T_{\min }$ is the minimum allowed temperature approach in the heat exchangers (defined as $5.0 \mathrm{~K}$ in this work, see Table 5). $\Delta T_{\text {pinch evaporator }}$ and $\Delta T_{\text {pinch gas cooler }}$ are process model values of the temperature pinch in the evaporator and gas cooler, respectively. Heat pump B includes IHX constraints by:

$$
q_{\mathrm{B}}=q_{\mathrm{A}}+k_{3} \cdot\left[\max \left(0, \Delta T_{\min }-\Delta T_{\text {pinch IHX }}\right)\right]^{2},
$$

while $C$ and $C^{*}$ implement the ejector efficiency $\eta_{\text {ejector }}$ with the help from a penalty added if the calculated $\eta_{\text {modelled ejector }}$ differs from $\eta_{\text {ejector }}$ (see Table 5):

$$
q_{\mathrm{C}}=q_{\mathrm{A}}+k_{4} \cdot\left[\left(\eta_{\text {modelled ejector }}-\eta_{\text {ejector }}\right)\right]^{2} .
$$




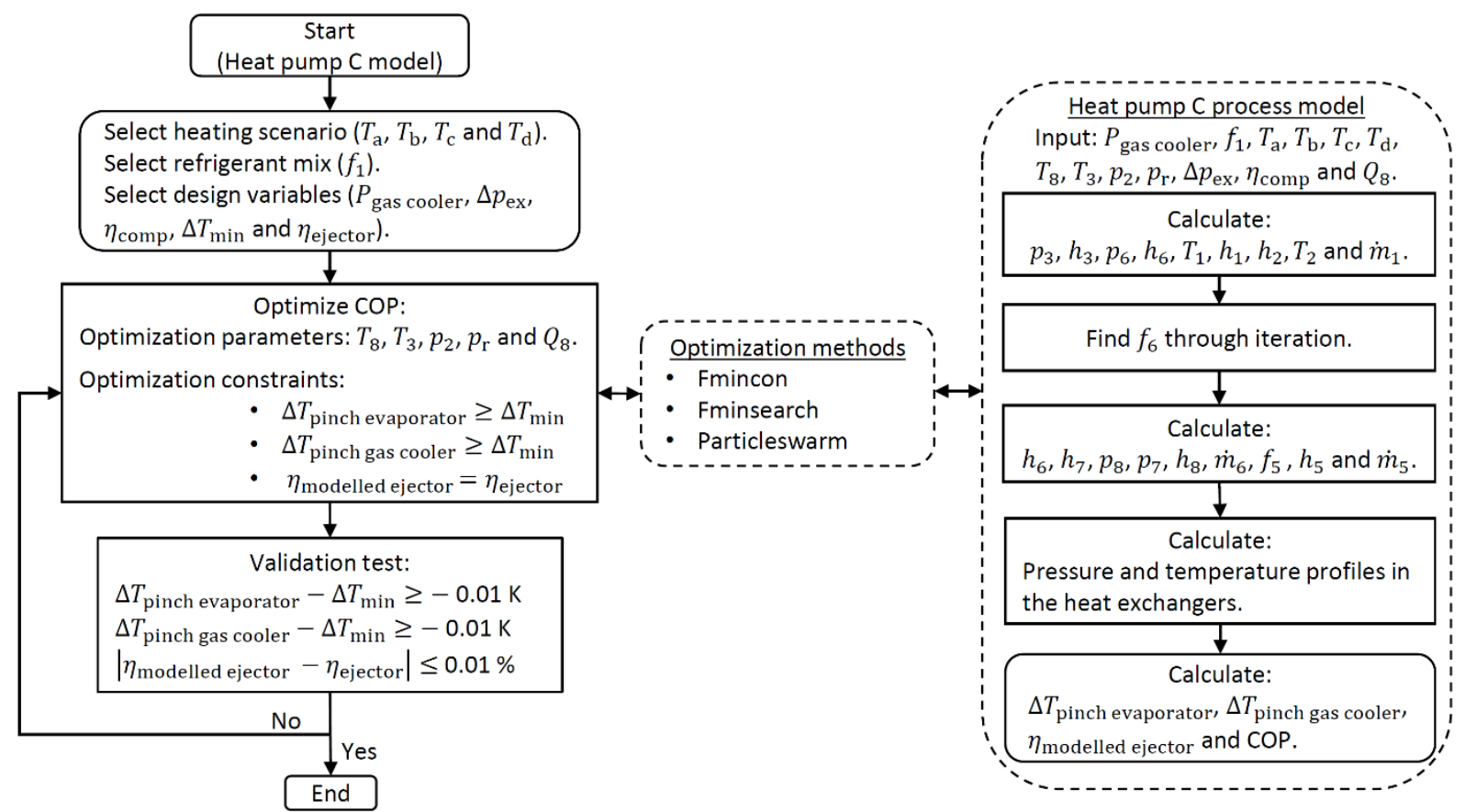

Figure 4. Flow chart of the main model structure and process calculations for the heat pump C design.

\subsection{Study Range and Design Variables}

Tap water is heated to $T_{\mathrm{b}}=70^{\circ} \mathrm{C}$ by the gas cooler, and chilled water at $T_{\mathrm{d}}=5^{\circ} \mathrm{C}$ is produced, making this study also relevant for combined heating and cooling applications. Five different heating scenarios are investigated (see Table 4). Scenario 1 and 2 represent systems where water is heated from $T_{\mathrm{a}}=15^{\circ} \mathrm{C}$ or $35^{\circ} \mathrm{C}$, respectively, using a heat source water stream where $T_{\mathrm{c}}=10^{\circ} \mathrm{C}$. Scenario 3 and 4 represent systems where the heat source and heat sink have the same inlet temperature $\left(T_{\mathrm{a}}=T_{\mathrm{c}}=15^{\circ} \mathrm{C}\right.$ or $\left.25^{\circ} \mathrm{C}\right)$. Scenario $5\left(T_{\mathrm{a}}=T_{\mathrm{c}}=45^{\circ} \mathrm{C}\right)$ is created to explore systems with a large temperature glide in the evaporator. Note that, for feed water temperatures above $40{ }^{\circ} \mathrm{C}, \mathrm{CO}_{2}$-based systems can be improved by integrating additional mechanical sub cooling (Dai et al., 2019a; Dai et al., 2019b).

Table 4. Heat source and heat sink scenarios.

\begin{tabular}{ll}
\hline Scenario 1 & $T_{\mathrm{a}}=15^{\circ} \mathrm{C}, T_{\mathrm{b}}=70^{\circ} \mathrm{C}, T_{\mathrm{c}}=10^{\circ} \mathrm{C}$ and $T_{\mathrm{d}}=5^{\circ} \mathrm{C}$ \\
\hline Scenario 2 & $T_{\mathrm{a}}=35^{\circ} \mathrm{C}, T_{\mathrm{b}}=70^{\circ} \mathrm{C}, T_{\mathrm{c}}=10^{\circ} \mathrm{C}$ and $T_{\mathrm{d}}=5^{\circ} \mathrm{C}$ \\
\hline Scenario 3 & $T_{\mathrm{a}}=15^{\circ} \mathrm{C}, T_{\mathrm{b}}=70^{\circ} \mathrm{C}, T_{\mathrm{c}}=15^{\circ} \mathrm{C}$ and $T_{\mathrm{d}}=5^{\circ} \mathrm{C}$ \\
\hline Scenario 4 & $T_{\mathrm{a}}=25^{\circ} \mathrm{C}, T_{\mathrm{b}}=70^{\circ} \mathrm{C}, T_{\mathrm{c}}=25^{\circ} \mathrm{C}$ and $T_{\mathrm{d}}=5^{\circ} \mathrm{C}$ \\
\hline Scenario 5 & $T_{\mathrm{a}}=45^{\circ} \mathrm{C}, T_{\mathrm{b}}=70^{\circ} \mathrm{C}, T_{\mathrm{c}}=45^{\circ} \mathrm{C}$ and $T_{\mathrm{d}}=5^{\circ} \mathrm{C}$ \\
\hline
\end{tabular}

The design parameters used to describe the refrigerant blend, compressor, ejector and heat exchanger performances in the modelling work are listed in Table 5. An isentropic compressor efficiency of 0.70 is used, based on a study by Brodal and Jackson (2019), where the HGX2/90-4 CO2 compressor from GEA, was suggested as an efficient compressor for hot water heating. This compressor operated at almost constant isentropic efficiency, between $0.69-0.70$, for different operating conditions typical for hot water heating applications. It has been claimed that $\mathrm{CO}_{2}$ ejectors operate with efficiencies between $0.20-0.30$, while the efficiency of ejectors for low-pressure refrigerants such as propane typically is less than 0.20 (Elbel and Lawrence, 2016). Due to the large variations, a sensitivity study is included for the ejector, assuming 0.17 and 0.34 to be a lower and an upper limit for $\mathrm{CO}_{2}$-based systems (Banasiak et al., 2012). For propane-based systems 0.17 is assumed to be a realistic ejector efficiency. The pinch temperature at the gas cooler/condenser, IHX and evaporator are all set to $5.0 \mathrm{~K}$ (Dai et al., 2015). A pressure drop of 0.2 bar was applied in all heat exchangers (evaporators, condensers and gas coolers), which is at the lower end of the pressure drop 
typical for such components (Gilberg, 2011). Hence, the results will not overstate the importance of the pressure drop, and the results are therefore expected to be more accurate than a zero pressure drop assumption, which is typically used in previous studies of blends such as by Sarkar and Bhattacharyya (2009) and Dai et al. (2015). Creating a more accurate model with individual heat exchanger pressure drop is outside the scope of this article.

Table 5. Design variables.

\begin{tabular}{ll}
\hline Input parameter & Value \\
\hline$P_{\text {gas cooler }}$ & $10 \mathrm{~kW}$ \\
\hline Mass fraction of $\mathrm{CO}_{2}$ at the compressor inlet & $0-1$ \\
$f_{1}=m_{\mathrm{CO} 2} /\left(m_{\mathrm{CO} 2}+m_{\text {propane }}\right)$ & \\
\hline Minimum allowed pinch temperature $\left(\Delta T_{\min }\right)$ & $5.0 \mathrm{~K}$ \\
\hline Pressure drop in heat exchangers $\left(\Delta p_{\mathrm{ex}}\right)$ & $0.2 \mathrm{bar}$ \\
\hline Compressor efficiency $\left(\eta_{\text {comp }}\right)$ & 0.70 \\
\hline Ejector efficiency $\left(\eta_{\text {ejector }}\right)$ & 0.17 and 0.34 \\
\hline
\end{tabular}

\section{Results}

COP for scenarios 1-5 is shown in Figure 5 with respect to the mass fraction $\mathrm{CO}_{2}$ entering the compressor. Figure 6 illustrates differences in composition between the gas and liquid in the receivers, and in heat pump $\mathrm{C}$ and $\mathrm{C}^{*}$, the "receiver liquid mass fraction" corresponds to the mass fraction circulating through the evaporator $\left(f_{6}\right)$. Different process data are illustrated in Figure 7. Heat pump C* (with $Q_{8}=1$ ) is only modelled for scenarios 1 and 2 , since the dew point requirement turned out to be an inefficent design compared to C (where $Q_{8} \leq 1$ ).
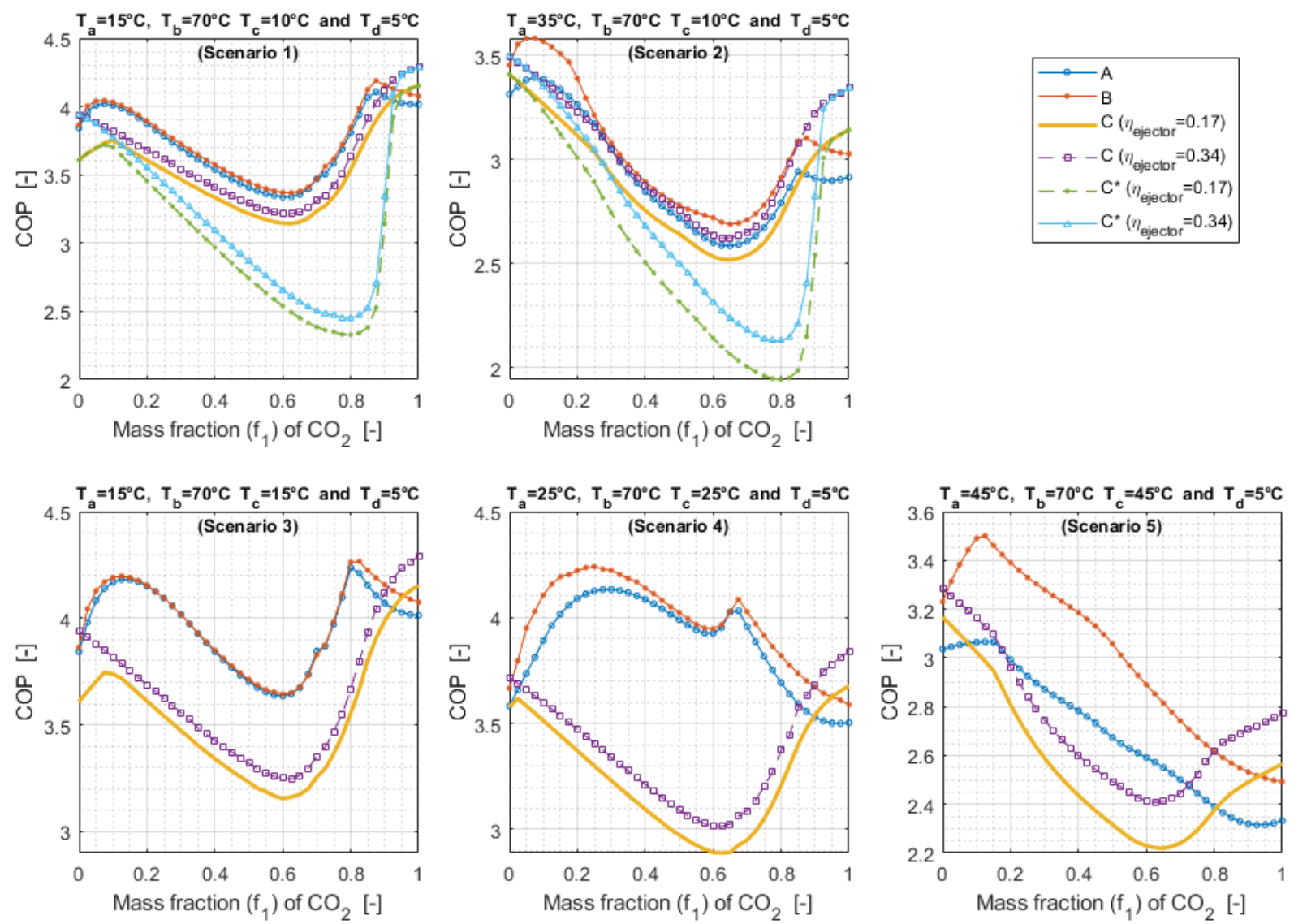

Figure 5. Optimized COP for heat pump design A, B, C and $C^{*}$ for heating scenarios 1-5. 


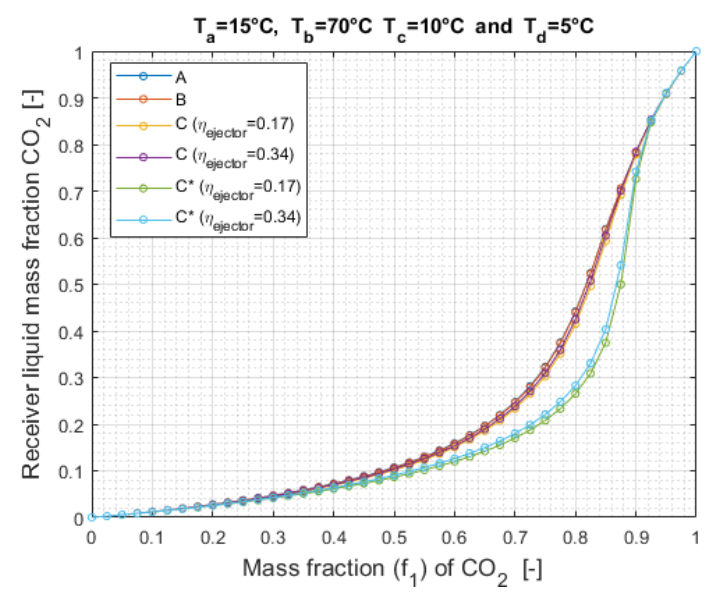

Figure 6. Gas phase versus liquid phase blends in the receiver, for heating scenario 1.
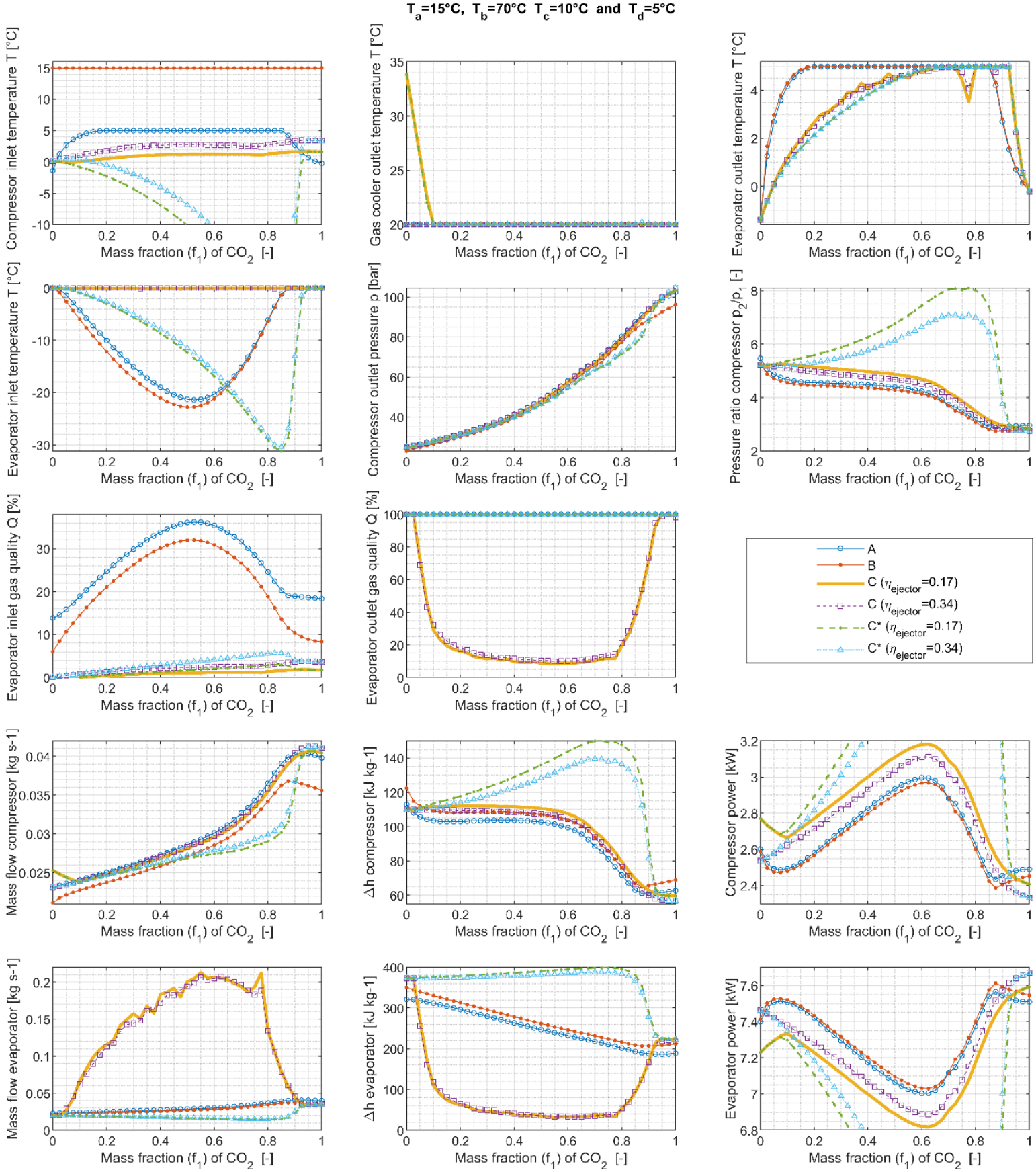

Figure 7. Different process data for optimized heat pumps operating at heating scenario 1. 


\section{Discussion}

There are different reasons for using refrigerant blends, one being that the blends can possess desired properties such as low flammability and low GWP (Zhang et al., 2017b), another being increased COP, as illustrated in Figure 5. Performance, modeling assumptions and findings are discussed below.

\subsection{Validation and Consistency}

A final tolerance is set in the optimization work to ensure that the results are meaningful. That is, all the results presented in this study violate the pinch temperature and the ejector efficiency by less than $0.01 \mathrm{~K}$ and a $0.01 \%$, respectively.

Efficient systems operate with a tight temperature approach, since the temperature approach in the heat exchangers is related to entropy generation and thermodynamical loss. This is reflected in the optimized results since all heat exchangers operate with minimum allowed temperature pinch, i.e. 5 $\mathrm{K}$. Optimized systems also operate with multiple $5 \mathrm{~K}$ temperature pinches in each exchanger if possible (see Figure $A$ and $B$ in the supplementary files).

Particleswarm uses a stochastically-based optimization algorithm designed for finding the global maximum, but even this algorithm can not guarantee that the optimal solution is found. However, the smoothness of the optimized results showing 41 different refrigerant mixtures of $\mathrm{CO}_{2}$ and propane for each heating scenario (see Figure 5), and the consistency of the optimized process parameters (see Figure 7), indicates that processes with a global maximum COP was found in all cases.

\subsection{Modeling Assumptions and Equipment Performance}

The main assumptions in this article are that equipment performance such as compressor efficiency and temperature pinch is assumed to be independent of the refrigerant blend, and that the heat exchanger designs are optimized for the given operating conditions. Models of real heat exchanger designs are complex and have many input parameters, and heat pump processes based on such models are therefore difficult to optimize and compare fairly, e.g. by cost. The minimum allowed temperature approach is a simplified method, based on the assumption that heat exchangers with similar temperature pinch are similar in size and therefore cost, even if important factors, such as the refrigeration blend, are changed. The simplicity of the minimum allowed temperature approach has gained much attention in optimization studies (Dai et al., 2015 and Sarkar and Bhattacharyya, 2009), since it makes it possible to discuss and compare different systems on a general basis. However, differences in the heat transfer are observed. The supplementary files show that inefficient systems and subcritical propane systems transfer heat with larger (average) temperature differences in the gas cooler, which is an argument as to why such systems should be modeled with a smaller temperature pinch. On the other hand, $\mathrm{CO}_{2}$ benefits from other factors such as efficient exchangers due to a large heat transfer coefficient (Cho et al., 2010), and smaller swept compressor volume is needed due to the high density at the evaporating pressure. It has also been claimed that the low $\mathrm{CO}_{2}$ pressure ratio is beneficial for the compressor efficiency (Stene and Alonso, 2016).

\subsection{Systems With and Without IHX}

Systems with zeotropic refrigerant blends and IHX (heat pump B) have earlier been investigated by Sarkar and Bhattacharyya (2009), but often are only systems without (A) modelled in such studies (Dai et al., 2015). However, the results presented in Figure 5 illustrate a significant benefit of using an $\mathrm{IHX}$ in some of the scenarios. That is, an IHX increases the COP in all the scenarios, in particular if the tap water temperature $T_{\mathrm{a}}$ is high, as in scenarios 2,4 and 5 . In scenario 4 and 2, COP improve 
respectively by $3 \%\left(f_{1} \approx 0.25\right)$ and $5 \%\left(f_{1} \approx 0.07\right)$. For scenario 5 , which was designed to explore more extreme situations favoring zeotropic blends, the gain was more than $14 \%\left(f_{1} \approx 0.12\right)$. The process parameters in Figure 7 illustrate that both systems have identical evaporator outlet temperature, but the systems with an IHX benefit from an approximately $10 \%$ lower vapor quality at the evaporator inlet. The IHX systems have a higher compressor inlet temperature, which results in a larger specific entropy increase in the compressor $\left(h_{2}-h_{1}\right)$, even though the compressor outlet pressure can be reduced while still providing the necessary heat.

\subsection{IHX Systems - Blend Versus Pure Refrigerant}

Figure 5 shows that heat pump B systems with an IHX obtain larger COP if a refrigerant blend is used instead of a pure refrigerant, since an energy efficient process uses a refrigerant that matches the temperature profile of the heat source and heat sink (see Figure A and B in the supplementary files). The improved COP obtained by using blends is therefore directly related to the increased outlet evaporator temperature of the refrigerant, as illustrated in Figure 7. Only in scenarios 1 and 3, with cold tapwater $\left(T_{\mathrm{a}}=15^{\circ} \mathrm{C}\right)$, were pure $\mathrm{CO}_{2}$-based $\left(f_{1}=1\right)$ systems better than pure propane-based $\left(f_{1}=\right.$ 0 ) systems. However, these $\mathrm{CO}_{2}$ systems improved COP with respectively $3 \%$ and $5 \%$ if the mass fraction of $\mathrm{CO}_{2}$ was reduced between 0.82 and 0.88 . Using a blend with $f_{1} \approx 0.05$ increased COP with $4 \%$ in scenario 2 . In scenario 4 , a $f_{1} \approx 0.25$ blend increased COP with $16 \%$.

\subsection{Pure Refrigerant Based Systems With and Without Ejector}

For pure $\mathrm{CO}_{2}$-based heat pumps, Figure 5 shows that systems with an ejector (C) are always more efficient than systems without (A), and the ejector gain is often significant ranging from 7-19\% increase in COP. In particular if the inlet tap water is above $25^{\circ} \mathrm{C}$, however, in such cases pure $\mathrm{CO}_{2}-$ based systems are inefficient compared to other alternatives. For pure propane-based heat pumps, COP is reduced by including an ejector in heating scenario 1,3 and 4 if the ejector efficiency is 0.17 . The reason being that the best method to provide the necessary energy to circulate the refrigerant through the evaporator system, with respect to COP, is to raise the gas cooler temperature (see Figure 7). This is not necessary if the ejector efficiency is 0.34 , which is unrealistically high for propane-based systems (Elbel and Lawrence, 2016). However, also in such extreme cases there is little to be gained by including an ejector in a system with pure propane, less than $3 \%$ increase in COP. Systems with propane are therefore more unlikely to be designed with an ejector. Figure 7 shows that if the pressure ratio over the compressor is reduced by inserting an ejector, the COP is increased due to reduction in the compressor power.

\subsection{Ejector Systems - Blend Versus Pure Refrigerant}

In neither of the cases studied did blend-based ejector systems (C) turn out to be the most energy efficient systems. The ejector reduces the thermodynamical losses in the expansion, but also introduces new losses related to the ejector efficiency. Additional losses are also introduced if a zeotropic refrigerant is used. For example, the different blends mixed inside the ejector (point 3 and 8 ) are not identical, as shown in Figure 3. Mixing of different chemical substances is an irreversible process generating entropy, since mixed fluids never spontaneously unmix (Starzak, 2010). Ejectors can also introduce a significant heat exchanger loss in systems with zeotropic mixtures if the evaporator inlet temperatures is reduced due to a large temperature glide (see Figure 4). The temperature glide becomes particularly large for certain zeotropic mixtures where the refrigerant is at dew point at the evaporator outlet $\left(C^{*}\right)$. Figure 7, for example, shows that the optimal inlet evaporator temperature in an ejector system with refrigerant blends can be $30^{\circ} \mathrm{C}$ colder than in systems with a pure refrigerant. If the mass flow through the evaporator is large, as is often the case for the heat pump C ejector design (see Figure 7), there are also more circulation losses related to the pressure drops in the expansion valve and the evaporator. 
As mentioned in the introduction, only a few papers have investigated zeotropic systems in combination with an ejector, and only five articles were identified modelling the different composition of the circulating refrigerants (Liu et al., 2015; Zhao et al., 2015; Li et al., 2016; Yan et al., 2016; Liu et al., 2018). However, neither of these modelled the temperature approach inside the heat exchangers, which is important since the main scope of such an investigation typically is to improve the performance (COP) by composing zeotropic refrigerants that match the temperature profile of the heating and cooling demand in the different exchangers.

The results presented in Figure 5 show that blends of $\mathrm{CO}_{2}$ and propane in combination with an ejector do not lead to efficient designs. This is the opposite of the findings typically reported earlier. However, the COP versus mass fraction data presented in these studies often shows similar trend as shown in Figure 5, even though these studies used more simplified heat exchanger models, and studied other blends and different processes. Zhao et al. (2015), for example, stated that maximum COP was found at 0.9 mass fraction blends. However, only systems with $0.1-0.9$ mass fraction blends were modelled in this study, and the results presented by Zhao et al. clearly indicate that systems with mass fractions outside the range being studied, such as pure refrigerants, performed better. Liu et al. (2015), Liu et al. (2018) and Yan et al. (2016) also concluded that the zeotropic mixture-based systems exhibited higher energy efficiency. However, these articles only studied blends with mass fractions between $0.3-0.7,0.3-0.7$ and $0.35-0.55$, respectively. Li et al. (2016) investigated zeotropic blends in an organic Rankine cycle with a combined heat pump. Li et al. did not conclude that it is inefficient to use blend-based systems with an ejector, however, the data presented show that pure refrigerant based systems obtained the largest COP for two of the three blends investigated. The third blend had maximum COP located outside the $0.7-1.0$ mass fractions range being studied.

Previous articles have also only studied zeotropic ejector systems where the refrigerant is at dew point at the evaporator outlet $\left(C^{*}\right)$, which is not necessarily the optimal configuration for zeotropic mixtures as illustrated by the results in Figure 5 . System design $C^{*}$ becomes inefficient since the evaporator inlet temperature has to be significantly reduced to satisfy the temperature pinch constraint (see Figure 3), which also relates to large pressure ratio for the compressor, as illustrated in Figure 7. The temperature glide through the evaporators in system $\mathrm{C}$ is sometimes reduced by optimizing the outlet vapor quality $Q_{8}$ with respect to COP.

\subsection{Performance - IHX Versus Ejector}

The most efficient systems $(C)$ with 0.17 ejector efficiency always had a lower COP than the most efficient systems with IHX (B), as illustrated by Figure 5. If the ejector efficiency is raised to 0.34 , there is a small gain in scenario 1 and 3 with a low tap water temperature $\left(T_{\mathrm{a}}=15^{\circ} \mathrm{C}\right)$. Scenario 1 has a small temperature reduction when the heat source is flowing through the evaporator $\left(T_{\mathrm{c}}-T_{\mathrm{d}}=5\right.$ $\mathrm{K})$. In this scenario, a pure $\mathrm{CO}_{2}$-based ejector system (C) obtained the best $\mathrm{COP}$, which was $2.5 \%$ higher than the best system with IHX (B). Scenario 3, which is similar to scenario 1 except that $T_{\mathrm{c}}-$ $T_{\mathrm{d}}=10 \mathrm{~K}$, obtained less than $1 \%$ gain in COP.

For all the scenarios with $T_{\mathrm{a}}$ equal or above $25^{\circ} \mathrm{C}$, i.e. scenario 2,4 and 5 , the optimal heat pump with an IHX (B) had a significant better COP than the other designs, and operated with blends having mass fractions of $\mathrm{CO}_{2}$ below 0.25 . In scenario 4 , where $T_{\mathrm{c}}-T_{\mathrm{d}}=20 \mathrm{~K}$, heat pump B obtains a $15 \%$ larger COP than the best system C.

\section{Conclusion}

This article investigates modifications for conventional transcritical $\mathrm{CO}_{2}$-based heat pump systems for water heating, and also presents a novel method to model blend-based ejector systems which include several important factors not previously considered. Such as implementing the ejector 
efficiency through a constraint in the optimization work, modeling systems where the zeotropic refrigerant is not necessarily at dew point when leaving the evaporator, and modelling ejector systems using a minimum temperature approach inside heat exchangers.

The results clearly state the importance of composing optimal zeotropic refrigerant blends that match the temperature profile of the heating and cooling demand in the different exchangers, and also show that COP can be improved in ejector systems with zeotropic blends by designing them with vapor quality $Q_{8}$ less than 1 at the evaporator outlet. However, the main finding is that blends with propane and $\mathrm{CO}_{2}$ are inefficient in systems with an ejector, and that such systems were always outperformed with either pure $\mathrm{CO}_{2}$-based ejector systems, or blend-based systems with an IHX.

For all the scenarios with tap water temperatures equal or above $25^{\circ} \mathrm{C}$, heat pumps with an IHX (B) operated with the highest COP using blends having mass fractions of $\mathrm{CO}_{2}$ below 0.25 . The difference in COP was sometimes as large as $15 \%$. Heat pumps with an IHX also obtained the best COP if the ejector efficiency is 0.17 or lower, or if the water temperature reduction in the evaporator $\left(T_{\mathrm{c}}-T_{\mathrm{d}}\right)$ is larger than $5 \mathrm{~K}$ if the ejector efficiency is slightly above 0.17 , and more than $10 \mathrm{~K}$ if the ejector efficiency is 0.34 . The model predicts that a $\mathrm{CO}_{2}$-based ejector system (C) obtains the highest COP if the tap water is cold, equal or below $15^{\circ} \mathrm{C}$. However, even with a large ejector efficiency of 0.34 , the gain in COP by using an ejector versus an IHX was always less than $2.5 \%$.

\section{REFERENCES}

Bai, T., Yan, G., Yu, J., 2018. Experimental investigation of an ejector-enhanced auto-cascade refrigeration system. Applied Thermal Engineering 129, 792-801.

Bai, T., Yan, G., Yu, J., 2019. Experimental investigation on the concentration distribution behaviors of mixture in an ejector enhanced auto-cascade refrigeration system. International Journal of Refrigeration 99, 145-152.

Banasiak, K., Hafner, A., Andresen, T., 2012. Experimental and numerical investigation of the influence of the two-phase ejector geometry on the performance of the R744 heat pump. International Journal of Refrigeration 35(6), 1617-1625.

Bell, I.H., Wronski, J., Quoilin, S., Lemort, V., 2014. Pure and Pseudo-pure Fluid Thermophysical Property Evaluation and the Open-Source Thermophysical Property Library CoolProp. Industrial \& Engineering Chemistry Research 53(6), 2498-2508.

Brodal, E., Jackson, S., 2019. A Comparative Study of $\mathrm{CO}_{2}$ Heat Pump Performance for Combined Space and Hot Water Heating. International Journal of Refrigeration 108, 234-245.

Cao, F., Song, Y., Li, M., 2019. Review on development of air source transcritical $\mathrm{CO}_{2}$ heat pump systems using direct-heated type and recirculating-heated type. International Journal of Refrigeration 104, 455-475.

Cho, J.M., Kim, Y.J., Kim, M.S., 2010. Experimental studies on the evaporative heat transfer and pressure drop of $\mathrm{CO}_{2}$ and $\mathrm{CO}_{2}$ /propane mixtures flowing upward in smooth and micro-fin tubes with outer diameter of $5 \mathrm{~mm}$ for an inclination angle of $45^{\circ}$. International Journal of Refrigeration 33(5), 922-931.

Dai, B., Dang, C., Li, M., Tian, H., Ma, Y., 2015. Thermodynamic performance assessment of carbon dioxide blends with low-global warming potential (GWP) working fluids for a heat pump water heater. International Journal of Refrigeration 56, 1-14.

Dai, B., Qi, H., Liu, S., Ma, M., Zhong, Z., Li, H., Song, M., Sun, Z., 2019a. Evaluation of transcritical $\mathrm{CO}_{2}$ heat pump system integrated with mechanical subcooling by utilizing energy, exergy and economic methodologies for residential heating. Energy Conversion and Management 192, 202-220. Dai, B., Qi, H., Liu, S., Zhong, Z., Li, H., Song, M., Ma, M., Sun, Z., 2019b. Environmental and economical analyses of transcritical $\mathrm{CO}_{2}$ heat pump combined with direct dedicated mechanical 
subcooling (DMS) for space heating in China. Energy Conversion and Management 198, Article 111078.

Ding, H., Sun, H., Sun, S., Chen, C., 2017. Analysis and optimisation of a mixed fluid cascade (MFC) process. Cryogenics 83, 35-49.

Elbel, S., Hrnjak, P., 2008. Experimental validation of a prototype ejector designed to reduce throttling losses encountered in transcritical R744 system operation. International Journal of Refrigeration 31(3), 411-422.

Elbel, S., Lawrence, N., 2016. Review of recent developments in advanced ejector technology. International Journal of Refrigeration 62, 1-18.

Gilberg, A.F., 2011. Development of a $\mathrm{CO}_{2}$ RSW system onboard a fishing vessel (Master of Science in Engineering and ICT). Norwegian University of Science and Technology, Trondheim.

Hernandez, J.I., Roman, R., Best, R., Dorantes, R., Gonzalez, H.E., 2014. The Behavior of an Ejector Cooling System Operating with Refrigerant Blends 410A and 507. Energy Procedia 57, 3021-3030. Kennedy, J., Eberhart, R. 1995. Particle swarm optimization. Proceedings of ICNN'95 - International Conference on Neural Networks.

Kunz, O., Wagner, W., 2012. The GERG-2008 Wide-Range Equation of State for Natural Gases and Other Mixtures: An Expansion of GERG-2004. Journal of Chemical \& Engineering Data 57(11), 30323091.

Lemmon, E.W., McLinden, M.O., Wagner, W., 2009. Thermodynamic Properties of Propane. III. A Reference Equation of State for Temperatures from the Melting Line to $650 \mathrm{~K}$ and Pressures up to $1000 \mathrm{MPa}$. Journal of Chemical \& Engineering Data 54(12), 3141-3180.

Li, Z., Li, W., Xu, B., 2016. Optimization of mixed working fluids for a novel trigeneration system based on organic Rankine cycle installed with heat pumps. Applied Thermal Engineering 94, 754-762.

Liu, X., Yu, J., Yan, G., 2015. Theoretical investigation on an ejector-expansion refrigeration cycle using zeotropic mixture R290/R600a for applications in domestic refrigerator/freezers. Applied Thermal Engineering 90, 703-710.

Liu, Y., Yu, J., Yan, G., 2018. Theoretical analysis of a double ejector-expansion autocascade refrigeration cycle using hydrocarbon mixture R290/R170. International Journal of Refrigeration 94, 33-39.

Lontsi, F., Hamandjoda, O., Sosso Mayi, O.T., Kemajou, A., 2016. Development and performance analysis of a multi-temperature combined compression/ejection refrigeration cycle using environment friendly refrigerants. International Journal of Refrigeration 69, 42-50.

Nekså, P., Rekstad, H., Zakeri, G.R., Schiefloe, P.A., 1998. CO CO $_{2}$ heat pump water heater: characteristics, system design and experimental results. International Journal of Refrigeration 21(3), 172-179.

Nelder, J.A., Mead, R., 1965. A Simplex Method for Function Minimization. The Computer Journal 7(4), 308-313.

Sarkar, J., Bhattacharyya, S., 2009. Assessment of blends of $\mathrm{CO}_{2}$ with butane and isobutane as working fluids for heat pump applications. International Journal of Thermal Sciences 48(7), 14601465.

Span, R., Eckermann, T., Herrig, S., Hielscher, S., Jäger, A., Thol, M., 2016. TREND. Thermodynamic Reference and Engineering Data 3.0. . Lehrstuhl für Thermodynamik, Ruhr-Universität Bochum. Span, R., Wagner, W., 1996. A New Equation of State for Carbon Dioxide Covering the Fluid Region from the Triple-Point Temperature to $1100 \mathrm{~K}$ at Pressures up to $800 \mathrm{MPa}$. Journal of Physical and Chemical Reference Data 25(6), 1509-1596.

Spellucci, P., 1998. A new technique for inconsistent QP problems in the SQP method. Mathematical Methods of Operations Research 47(3), 355-400.

Starzak, M.E., 2010. Energy and Entropy: Equilibrium to Stationary States. Springer New York. Stene, J., Alonso, M.J., 2016. Field Measurements - Heat Pump Systems in NZEB. SINTEF Academic Press.

Tashtoush, B.M., Al-Nimr, M.d.A., Khasawneh, M.A., 2019. A comprehensive review of ejector design, performance, and applications. Applied Energy 240, 138-172. 
Yan, G., Bai, T., Yu, J., 2016. Thermodynamic analysis on a modified ejector expansion refrigeration cycle with zeotropic mixture (R290/R600a) for freezers. Energy 95, 144-154.

Zhang, X., Wang, F., Fan, X., Duan, H., Zhu, F., 2017a. An investigation of a heat pump system using $\mathrm{CO}_{2}$ /propane mixture as a working fluid. International Journal of Green Energy 14(1), 105-111.

Zhang, Y., Deng, S., Ni, J., Zhao, L., Yang, X., Li, M., 2017b. A literature research on feasible application of mixed working fluid in flexible distributed energy system. Energy 137, 377-390.

Zhao, L., Yang, X., Deng, S., Li, H., Yu, Z., 2015. Performance analysis of the ejector-expansion refrigeration cycle using zeotropic mixtures. International Journal of Refrigeration 57, 197-207. 